\title{
Fuzzy Logic Based Smart Home Automation and Forecasting Electric Energy Consumption
}

\author{
Abdulkadir Gozuoglu and Okan Ozgonenel
}

\begin{abstract}
Monitor and control home electrical network in smarter way creates the base of Smart Grid technology while presenting solutions for energy crisis. The main purpose of this study is to implement a low-cost smart controller system for Smart Homes based on fuzzy logic functions, reducing unnecessary energy consumption, estimating the consumption by using time series applications. Forecasting and controlling the consumption in customer side makes the creation of load profiles easier. The created load profiles increase the efficiency while managing MV network with smart grid applications. In the study, STM32 microcontroller is the brain of the system. On the other hand, as software part Processing and Matlab is used.
\end{abstract}

Index Terms - Home network monitoring and control; Smart homes; fuzzy logic; time series analysis; energy consumption forecast.

\section{INTRODUCTION}

$\mathrm{T}$ HE ELECTRICITY is one of the most important energy types in the world. Electrical energy crisis is also one of the big problems that alt world may face [1]. Energy crisis has effect on both sociological and economical areas [2, 3]. Electrical energy consumers may encounter with cut of energy due to inefficient energy generation [2, 4]. Smart Grids application is emerged to overcome the problems during electrical energy generation, transmission and distribution stages [4, 5]. Smart Homes plays important role while delivering electrical energy to the consumers [4]. In this way, every consumer takes part to lower the electrical power consumption $[1,6]$ and this structure will affect electrical demand on over the world.

Babu et al. [1] have designed fuzzy logic based smart home application that uses smart meters to control home appliances. The home automation system is managed by micro controllers and smart meters have automatic switching hardware. Another

ABDULKADIR GOZUOGLU, is with Department of Electrical and Energy, Tokat Gaziosmanpasa University, Tokat, Turkey, (e-mail: abdulkadir.gozuoglu@gop.edu.tr).

iD https://orcid.org/ 0000-0002-6968-379X

OKAN OZGONENEL, is with Department of Electrical and Electronics Engineering, Ondokuz Mayis University, Samsun, Turkey, (e-mail: okanoz@omu.edu.tr).

iD https://orcid.org/ 0000-0001-9995-1460

Manuscript received April 26, 2021; accepted September 1, 2021. DOI: $10.17694 /$ bajece. 928537 home automation system was proposed by Han et al. which is controlled by user commands with combination of smart sensors and communication network pioneering [7]. The smart sensors and communication network commands are implemented especially on heating and cooling system in the house. Han et al. [8] were developed a new ZigBee communication protocol that could be used for smart home energy management applications. [9] has mentioned about RFID and IoT applications for smart homes. [10] has prepared an algorithm for energy management by including renewable energy sources. Kim et al. [11] were proposed Smart Home Protocol to connect Smart Home and electrical home appliances together. In another study, new system was discussed to monitor appliances continuously and put them OFF state when not being used during a certain period of time [12].

The heating and cooling systems in residential type consumers carry high weight with energy consumption [13, 14]. These systems are usually operating with constant power mode. The control stages of these loads are generally as ON and OFF control. Using Fuzzy Logic control functions increases the control stages [13]. Afram et al. [15] has carried out a control method for heating and cooling systems.

The classical control method for lighting system in building is ON-OFF control type [16]. But nowadays according to the technological improvements dimmer circuits usage became more famous. This application became more efficient by combining microcontroller, sensor and automation systems together $[17,18]$.

In our study, we propose a controller to monitor and control the overall energy consumption of houses. The controller was prepared according to the fuzzy logic rules. The input signals are captured by fuzzy logic controller and the output parameters are calculated according to the pre-defined rules [13].

The energy measurement was performed at entrance of the houses. On the other hand, temperature, humidity and light luminosity are measured for controlling heating, cooling and lighting appliances. STM32 was use as microcontroller in the hearth of the system. RF (Radio Frequency) method was used for communication between hardware systems [7, 8]. To perform RF communication nrf24101 module [19] was used instead of ZigBee modules to be able to lower the price. One of the main aims of the study is to perform high level controller with low-cost equipment and offer consumer smart homes with relatively low-level prices. As user interface 3.2inch Nextion touch screen was used. But according to 
consumer requests an Android or PC compatible Scada interface also could be performed.

\section{THE OVERVIEW OF PROPOSED SYSTEM}

The Smart Home application's hardware part has two main portions. These are slave modules and master module. Master module also called as RTU (Remote Terminal Unit). RTU is the brain of the system and it makes decisions for every situation. In RTU STM32 (STM32F401RET6) board was used as micro controller. RTU collects all the information from slave modules via RF communication. The control method is Fuzzy Logic. RTU gets input signals, process them according to fuzzy logic rules and finally calculates the output functions. On the other hand, RTU is in charge with all measurement and signal values to monitor in Scada interface and save them in prebuilt database. All the values which are save in database are also analysed in Matlab environment to be able to estimate future energy consumptions.

In slave modules ATmega328 base Arduino Pro Mini boards are used as micro controller. Slave\#1 works as energy meter. It is connected in the entrance of the house and it measures current, voltage, power, energy and power factor according to the total consumption. Slave\#2 measures temperature, humidity and luminosity of the environment. The general working principal of our study is shown in Fig. 1.

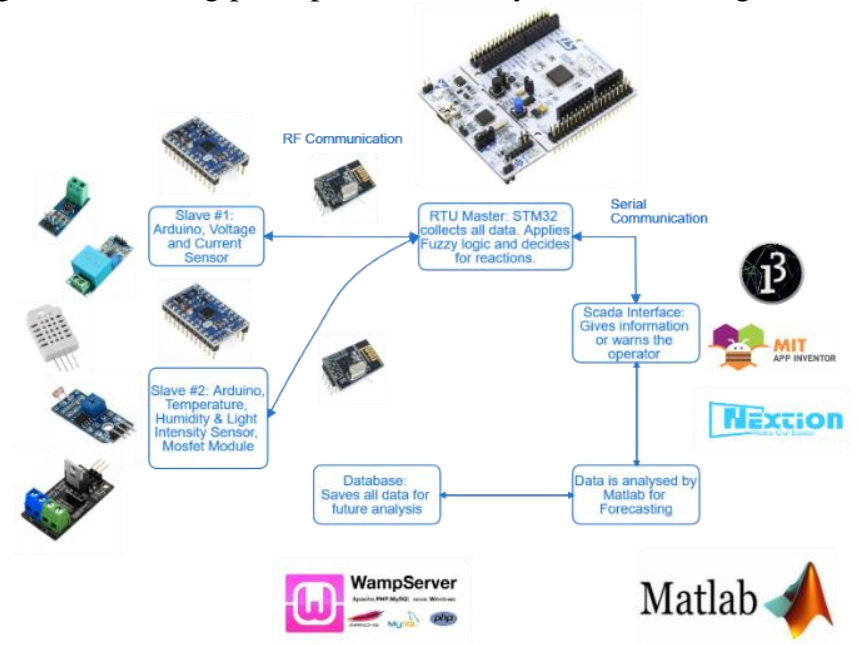

Fig. 1. General working Algorithm

The voltage sensor operates between $0-250 \mathrm{~V}$. The current sensor can measure current between $0-25 \mathrm{~A}$. Used temperature and humidity sensor range is $-40 \sim 80^{\circ} \mathrm{C}$ and $0-100 \%$ respectively.

The communication between RTU and slave modules is performed by using nrf24101 modules via RF communication. Nrf24 modules can operates over 125 different channels with the frequency range between $2400-2525 \mathrm{Mhz}$. The module can perform different data rates by using unique IDs.

In our study MySQL database [20] was used to be able to save fuzzy logic analysis outputs, for various reporting and for retroactive analysis of the saved data. These data also used by Matlab application to be able to perform Time Series Analysis for future consumption estimations.

Time Series Analysis [21] is used to make estimations and calculate future values according to used analysis model and past data [22]. In our study, the measurement and fuzzy logic output functions are handled with autoregressive model and analysed by using time series function in Matlab environment. The results of the time series analysis gave us future estimated data. According the comparison test between real data and estimated data, it was seen that the difference is very low.

\section{Smart CONTROller BASEd On FuZZY LoGiC}

The Fuzzy Logic control system manages the process according to the predefined rules which are composed of word arguments [23]. The rule number is defined according to the input membership functions [13]. In our study there are 25 rules for cooling-heating systems, 5 rules for lighting system and 5 rules for energy consumption totally 35 rules.

Smart controller system calculates appropriate output signals according to 4 input data. The input variables are defined as Temp, Hum, Luminosity and Electrical Energy. While defining each input membership functions different limit values have been used. The limit values for Temp variable are between $(-5)-55^{\circ} \mathrm{C}$. The limit values for Hum variable are between $0 \%-100 \%$. The limit values for Luminosity variable are between $0 \%-100 \%$. The limit values for Energy variable are between 0-250kWh.

The output signal variables are defined as A/C Power, Light_Intensity and Electrical_Bill. The equations according to triangle membership functions are listed in Equation (1). In triangle function $\mathrm{a}, \mathrm{b}, \mathrm{c}$ are lower limit, high limit and top value respectively.

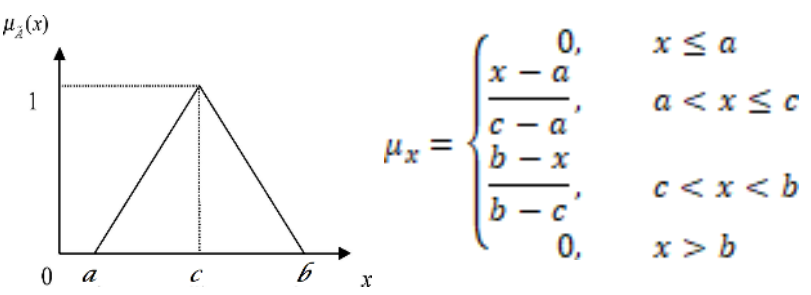

The fuzzification is applied to the input signals by using triangle functions. By using input values and fuzzy logic rules, the fuzzified output values are obtained. After defuzzification process is applied to the output values, we can get exact values. Appling Centre of Average method all these exact values are converted into single output value [13]. Single output value is obtained according to Equation (2). In this equation $U$ defines defuzzification result, $u$ is for output variable, $\mathrm{p}$ is the single result value number, $\mu$ is the membership function value and i defines index value.

$$
U=\frac{\sum_{i=1}^{p}\left[u_{i} \mu_{i}\right]}{\sum_{i=1}^{p}\left[\mu_{i}\right]}
$$

Fig. 2. The relation between temperature, humidity and motor power shows the effect of temperature and humidity measurement of the environment on motor power inside the heating and cooling systems. As the temperature is high cooling system's motor starts running and when the temperature decreases the heating system's motor starts to run and increases the consumed power. On the other hand, the humidity value also effects the motor power. The smart 
controller tries to balance the heating and cooling system's motors. By using fuzzy logic methods, the control stages and rules became more then $0-1$ and the resolution of the control stages increase compared with classic control methods.

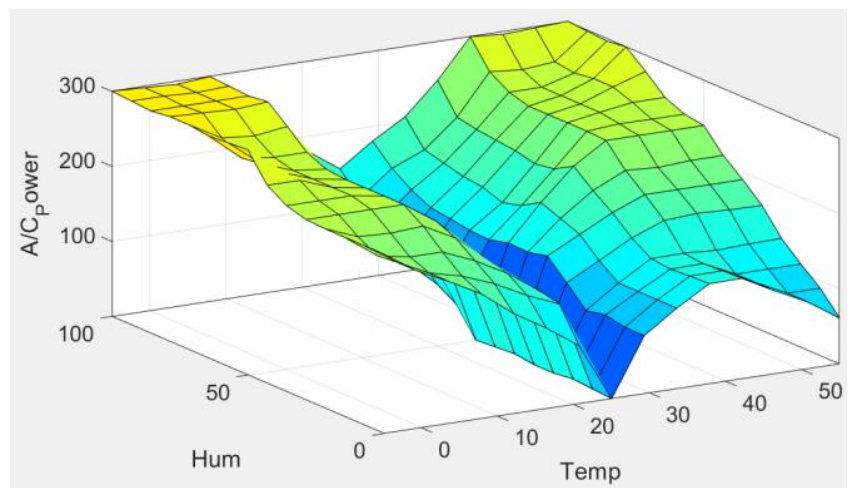

Fig. 2. The relation between temperature, humidity and motor power

Fig. 3 shows the relation between light intensity and luminosity. It could be seen that the PWM controlled light source signal changes inverse proportional with the light intensity of the environment. Decreasing in light intensity of the environment results with increasing of the duty cycle of PWM signal and so increase in the luminosity of the lighting equipment. With this manner we could get more efficient consumption style compared with classic on-off method. On the other hand, in Fig. 4 it is seen that the relation between real time energy consumption and the electrical bill price.

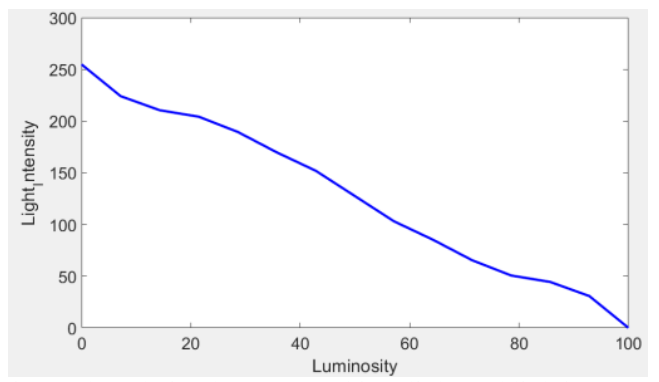

Fig. 3.The relation between ambient light and lighting systems

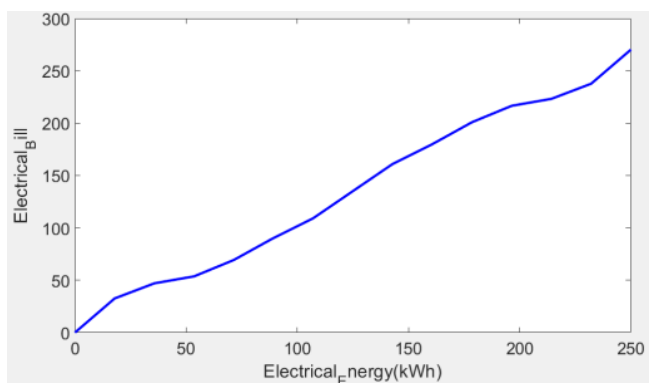

Fig. 4. The relation between energy consumption and electrical bill

\section{TIME SERIES ANALYSIS AND CONSUMPTION FORECAST}

Time Series Analysis give opportunities to estimate future values of the data by analysing past data with the combination of appropriate model [21]. In our study, the hardware part of the system controls the home appliances according to need of consumer with maximum efficiency and operate the switches automatically by using fuzzy logic controller. Besides, the system also gives information to the consumer about the bill price according to consumed energy. On the other hand, by using Time Series Analysis method the system also estimates the future electrical bill prices according to past consumption behaviour. The data used by time series is the measurement active power values saved in to database with one minute interval [24]. To use the data in the analysis first average calculation performed for 1-hour data and so twelve mount data was used for time series calculations. The data could be seen in Fig. 7.

In our study, to implement time series analysis Box Jenkins method was used [25]. This method determines all the models and chooses the most appropriate one and estimate the future data [21]. First stage, the series' stationery, trend stationery and difference stationery situations are examined and the series is converted to stationery format. Autocorrelation (ACF) and partial autocorrelation (PACF) graphs of the series which is converted to stationery are analysed. According to analysis of the ACF and PACF graphs a decision should be made to use appropriate model for the data. These models could be autoregressive (AR) model, moving-average (MA) model or autoregressive-moving-average (ARMA) model. According to the chosen model appropriate coefficients are determined. As a result of these stages and by using past data future estimates are performed. According to data in Fig. 7 there is no seasonality in the data. Besides, there is also no fixed direction increasing and decreasing situations in the graph. Equation (3) and Equation (4) are used to calculate ACF and PACF curves and so analyse the data [25].

$$
\begin{gathered}
\rho_{k}=\frac{E\left[\left(X_{t}-\mu_{t}\right)\left(X_{t+h}-\mu_{t+\hbar \hbar}\right)\right]}{\sqrt{E\left[\left(X_{t}-\mu_{t}\right)^{2}\left(X_{t+h}-\mu_{t+\hbar}\right)^{2}\right]}} \\
\alpha_{k}=\operatorname{cor}\left(X_{k+1}-P_{s p} X_{k+1}, X_{1}-X_{s p} X_{1}\right) k \geq 2
\end{gathered}
$$

In the equations above $\mathrm{X}_{\mathrm{t}}$ defines the stationery time series, $\mu t$ is the mean of the series, $h$ is lagging number, $E$ is the expected value and $\mathrm{P}_{\mathrm{sp}} \mathrm{X}$ is the process of reflection of $\mathrm{X}$ along $1, X_{2}, \ldots, X_{k}$ values. The ACF curve of the time series is shown in Fig. 5.

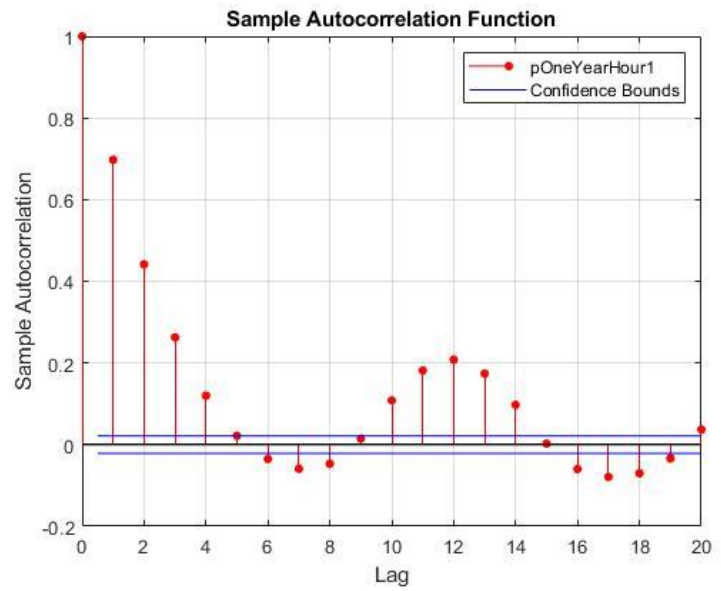

Fig. 5. Autocorrelation function 
The partial autocorrelation (PACF) curve of the time series also could be seen in Fig. 6.

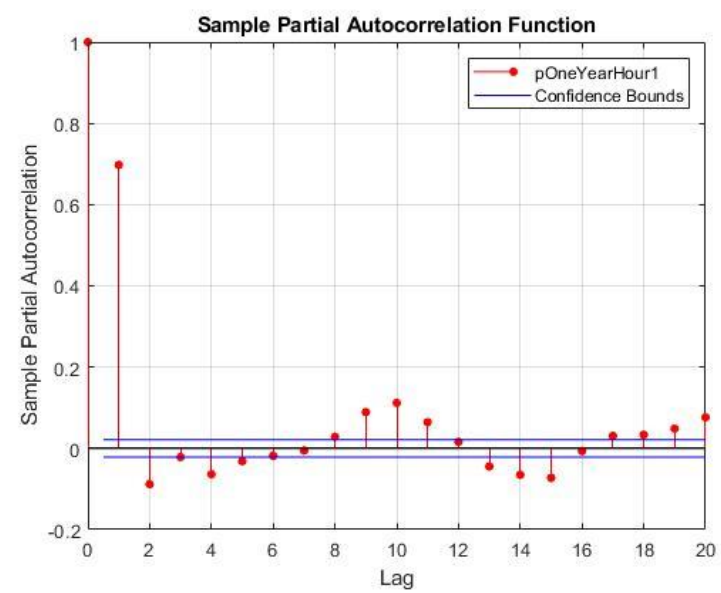

Fig. 6. Partial autocorrelation function

According to ACF curve of time series after 4th lag it could be seen that the curve oscillates periodically. This situation shows that the past values are effective for forecasting future data. For this reason, according to data type and time series behaviour autoregressive model was chosen. The time series is modelled with AR(4), et N(0, 0.4005) and by using Equation (5). According to used model 3-month consumption estimations could be seen in Fig. 7.

$$
\begin{aligned}
y(t)=e_{t}-0.8621 y_{t-1}+ & 0.0529 y_{t-2} \\
& -0.0500 y_{t-8}-0.0425 y_{t-4}
\end{aligned}
$$

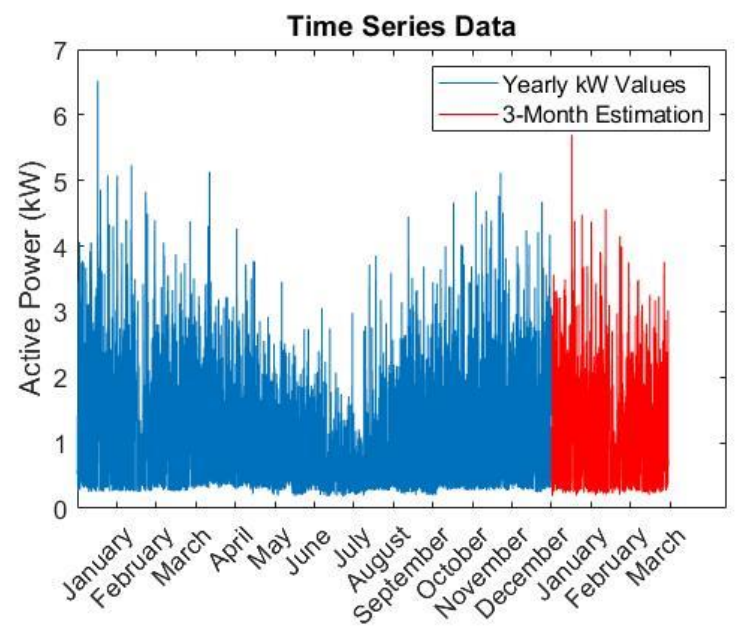

Fig. 7. One-year consumptions measurements and 3-month consumption forecast

According to performed estimation values, Fig. 8 shows the residual histogram. It could be seen that the residual histogram is normally distributed and it is in expectable ranges.

It is also important to perform some statistical analysis on forecasting data. For comparing forecasting data with base data three error analysis was performed. These are Mean Absolute Error (MAE), Mean Absolute Percentage Error (MAPE) and Root Mean Squared Error (RMSE). The analysis was performed according to the Equations (6), (7), (8) and the results could be seen in Fig. 9. The error analysis shows that the forecasting data is close to the original data.

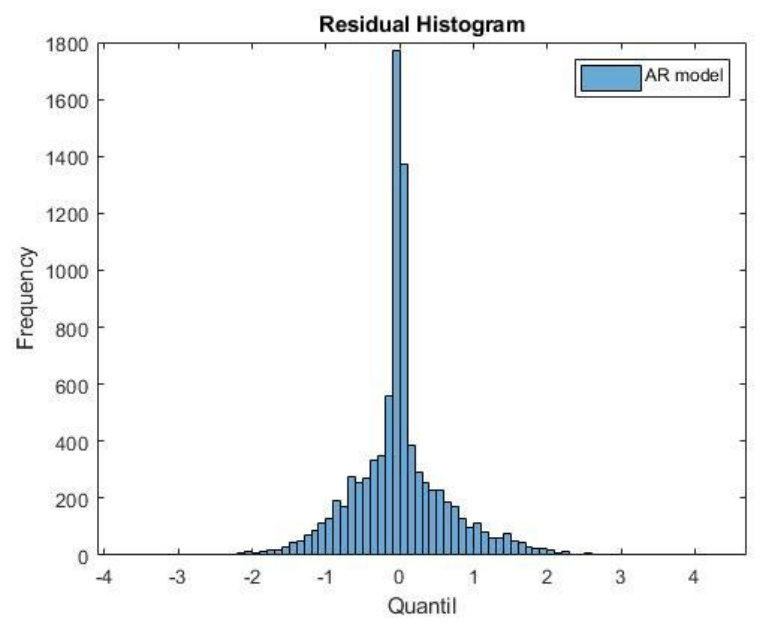

Fig. 8. Residual histogram analysis

$$
\begin{gathered}
\text { MAE }=\frac{1}{n} \sum_{t=1}^{n}\left|e_{t}\right| \\
\text { MAPE }=\frac{100 \%}{n} \sum_{t=1}^{n}\left|\frac{e_{t}}{y_{t}}\right| \\
\text { RMSE }=\sqrt{\frac{1}{n} \sum_{t=1}^{n} e_{t}^{2}}
\end{gathered}
$$

\begin{tabular}{||l|c|}
\hline \multicolumn{2}{|c|}{ Error Analysis for Forecasting Data } \\
\hline Mean Absolute Error (MAE) & 0,4879 \\
\hline Mean Absolute Percentage Error (MAPE) & 46,0312 \\
\hline Root Mean Squared Error (RMSE) & 0,7206 \\
\hline
\end{tabular}

Fig. 9. Error analysis for forecasting data

\section{RESULTS}

The Smart Homes are really important subject for future Smart Grids. Our study is an application of home automation system to improve the smartness of Smart Homes. Instead of Classical Control methods Fuzzy Logic Controller was used. Using this controller improve the resolution of the controlling

\begin{tabular}{|c|c|c|c|}
\hline \multicolumn{2}{|c|}{ DIY Version } & \multicolumn{2}{|c|}{ Commercial Version } \\
\hline Item Description & Approximate Cost & Item Description & Approximate Cost \\
\hline Wifi Relay (On-Off) & €60,00 & Wifi Relay (On-Off) & €200,00 \\
\hline Wifi Mosfet Controller & €75,00 & Wifi Mosfet Controller & €250,00 \\
\hline Main Server Processor & $£ 750,00$ & Main Server Processor & $€ 3.500,00$ \\
\hline Spare Controller & $£ 100,00$ & Spare Controller & £750,00 \\
\hline Touch Screen & $€ 750,00$ & Touch Screen & $£ 2.000,00$ \\
\hline Current Sensor & $€ 100,00$ & Current Sensor & $€ 500,00$ \\
\hline Voltage Sensor & $€ 50,00$ & Voltage Sensor & $£ 500,00$ \\
\hline
\end{tabular}
system and so it could handle all possible stages while giving decisions. The main purpose of using this type of controller is to increase the efficiency level of consumed electrical energy in houses.

Fig. 10. Cost Comparison between DIY \& Commercial Versions

The comparison between DIY and commercial versions of the appliances could be seen in Fig. 10. The cost values are approximated. But the value levels show the difference between two systems. The commercial ones usually stand in 
very high levels. The listed items do not cover all the system appliances. These ones are added just to compare two mediums.

The Time Series applications used in our study helps us to estimate the monthly electrical energy consumptions of the houses. Future energy estimations also facilitate for creation of load profiles for each consumer. Getting the load profile information for every consumer is important especially for MV electrical network. MV Smart Grids could analyse the load demand levels and manage energy generation plants in more accurate ways.

\section{REFERENCES}

[1] V. S. Babu, U. A. Kumar, R. Priyadharshini, K. Premkumar, and S. Nithin, "An intelligent controller for smart home," in 2016 International Conference on Advances in Computing, Communications and Informatics (ICACCI), 2016, pp. 2654-2657.

[2] A. Datta, P. Mohanty, and M. Gujar, "Accelerated deployment of Smart Grid technologies in India - Present scenario, challenges and way forward," in ISGT 2014, 2014, pp. 1-5.

[3] S. Nithin, P. Sivraj, K. K. Sasi, and R. Lagerstöm, "Development of a Real Time Data Collection Unit for distribution network in a smart grid environment," in 2014 Power and Energy Systems: Towards Sustainable Energy, 2014, pp. 1-5.

[4] J. Li, L. Da-You, and Y. Bo, "Smart home research," in Proceedings of 2004 International Conference on Machine Learning and Cybernetics (IEEE Cat. No.04EX826), 2004, pp. 659-663 vol.2.

[5] Z. Fan, G. Kalogridis, C. Efthymiou, M. Sooriyabandara, M. Serizawa, and J. McGeehan, The new frontier of communications research, 2010.

[6] M. K. Paramathma, D. Devaraj, V. A. I. Selvi, and M. Karuppasamypandian, "Development of Fuzzy Logic Based Approach for Consumer Side Management in Smart Home," in 2021 International Conference on Advance Computing and Innovative Technologies in Engineering (ICACITE), 2021, pp. 1056-1061.

[7] D. Han and J. Lim, "Smart home energy management system using IEEE 802.15.4 and zigbee," IEEE Transactions on Consumer Electronics, vol. 56, pp. 1403-1410, 2010.

[8] D. Han and J. Lim, "Design and implementation of smart home energy management systems based on zigbee," IEEE Transactions on Consumer Electronics, vol. 56, pp. 1417-1425, 2010.

[9] M. Darianian and M. P. Michael, "Smart Home Mobile RFIDBased Internet-of-Things Systems and Services," in 2008 International Conference on Advanced Computer Theory and Engineering, 2008, pp. 116-120.

[10] A. R. Boynuegri, B. Yagcitekin, M. Baysal, A. Karakas, and M. Uzunoglu, "Energy management algorithm for smart home with renewable energy sources," in 4th International Conference on Power Engineering, Energy and Electrical Drives, 2013, pp. 17531758.

[11] S. Kim, J. Hong, S. Kim, S. Kim, J. Kim, and J. Chun, "Restful Design and Implementation of Smart Appliances for Smart Home," in 2014 IEEE 11th Intl Conf on Ubiquitous Intelligence and Computing and 2014 IEEE 11th Intl Conf on Autonomic and Trusted Computing and 2014 IEEE 14th Intl Conf on Scalable Computing and Communications and Its Associated Workshops, 2014, pp. 717-722.

[12] J. Lim, H. Son, B. Shin, and D. Lee, "CASPRE: A context-aware standby power reduction scheme for household appliances," in 2016 IEEE International Conference on Pervasive Computing and Communication Workshops (PerCom Workshops), 2016, pp. 1-6.

[13] S. A. u. R. Omer and E. Muhammad, "Design of intelligent air conditioner controller using fuzzy logic," in 2017 International Conference on Innovations in Electrical Engineering and Computational Technologies (ICIEECT), 2017, pp. 1-5.
[14] M. Zareb, B. Bakhti, Y. Bouzid, C. E. Batista, I. Ternifi, and M. Abdenour, "An Intelligent IoT Fuzzy Based Approach for Automated Indoor Air Quality Monitoring," in 2021 29th Mediterranean Conference on Control and Automation (MED), 2021, pp. 770-775.

[15] A. Afram and F. Janabi-Sharifi, "Theory and applications of HVAC control systems - A review of model predictive control (MPC)," Building and Environment, vol. 72, pp. 343-355, 2014/02/01/ 2014.

[16] R. B. Caldo, J. T. Seranilla, D. J. Castillo, K. S. Diocales, W. D. Gulle, B. L. Nuňez, et al., "Design and development of fuzzy logic controlled dimming lighting system using Arduino microcontroller," in 2015 International Conference on Humanoid, Nanotechnology, Information Technology,Communication and Control, Environment and Management (HNICEM), 2015, pp. 1-6.

[17] R. D. Katznelson and J. Howells. Bepress. (2018, Feb 14). Inventing around Edison's lamp patent: the role of patents in stimulating downstream development and competition [Online]. Available:

http://works.bepress.com/cgi/viewcontent.cgi?article=1073\&conte $\mathrm{xt}=$ rkatznelson

[18] P. Dimitroulis and M. Alamaniotis, "Residential Energy Management System utilizing Fuzzy Based Decision-Making," in 2020 IEEE Texas Power and Energy Conference (TPEC), 2020, pp. 1-6.

[19] A. Gozuoglu, O. Ozgonenel, and S. Karagol, "Fuzzy Logic Based Low Cost Smart Home Application," in 11th International Conference on Electrical and Electronics Engineering (Eleco2019), Bursa, 2019.

[20] A. Gozuoglu and O. Ozgonenel, "Ak1llı Şebeke ve Scada Benzeşimi için Eğitim Takımı Tasarımı," in Elektrik-Elektronik ve Biyomedikal Mühendisliği Konferansı (Eleco2018), Bursa, 2018.

[21] Ç. Kurnaz and B. K. Engiz, "Bir Ortamdaki Elektrik Alan Şiddetinin Zaman Serisi Analizi ile Belirlenmesi," Uluslararast Mühendislik Araştırma ve Geliş̧tirme Dergisi, vol. 10, pp. 29-35, 2018.

[22] R. E. Abdel-Aal and A. Z. Al-Garni, "Forecasting monthly electric energy consumption in eastern Saudi Arabia using univariate timeseries analysis," Energy, vol. 22, pp. 1059-1069, 1997/11/01/ 1997.

[23] J. Jantzen, Foundations of fuzzy control. A practical approach, 2nd ed. Chichester, UK: Wiley, 2013.

[24] U. I. S. o. I. a. C. Science. (2018, 24.04.2021). Household Power Consumption. Available: https://data.world/uci/individualhousehold-electric-power-

consumption/workspace/file?filename=household_power_consum ption.txt

[25] G. E. P. Box, G. M. Jenkins, and G. C. Reinsel, Time Series Analysis: Forecasting and Control. Hoboken, NJ, USA: Wiley, 2008.

\section{BIOGRAPHIES}

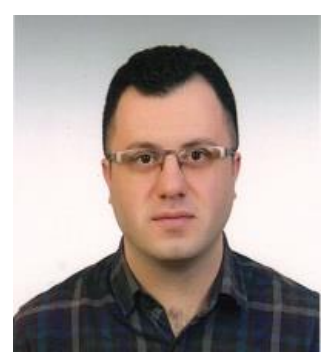

Abdulkadir GOZUOGLU was born in Mardin in 1988. He received his B.S degree from Gaziantep University in 2011 as Honor Student. He received his MSc. Degree from Ondokuz Mayis University in 2018. His Ph.D. education continues in Ondokuz Mayis University in Electrical and Electronics Engineering Department.

He is currently lecturer with the Department of Electrical and Energy, in Tokat Gaziosmanpasa University.

His current research interest includes the smart grids,smart homes, fuzzy logic, deep learning, embedded systems, electrical network transmission and distribution, automatic monitoring and control. 


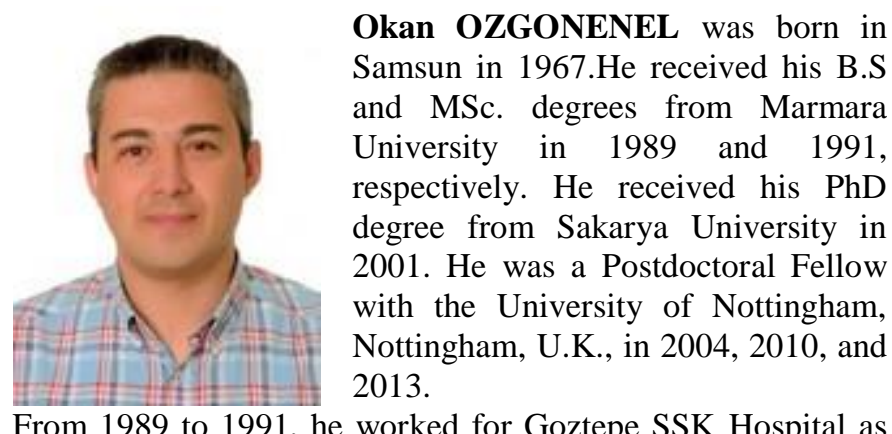
an engineer. Then he received a special grant and promoted as Lecturer in Amasya Technical and Vocational Higher School by means of World Bank Second Industrial Training Project. He has worked there for 10 years and then joined Ondokuz Mayis University, Electrical \& Electronic Engineering Department in 2002. He was promoted as full Professor in 2014 and since then he has been working for Ondokuz Mayis University.

His main research interests are digital algorithms, renewable energies, simulation methods for power transformers, power system control and protection, and wavelet techniques. 